\title{
Evaluation of Robinson's cytological grading by comparing it with modified Bloom- Richardson's histological grading for infiltrating ductal carcinoma of Breast
}

\author{
Chiragkumar B. Menapara' ${ }^{1, *}$, Mayur Kokani ${ }^{2}$ \\ Assistant Professor, Dept. of Pathology, GMERS Medical College \& Hospital, Junagadh, Gujarat, India
}

Corresponding Author:

Email: chirmen123@gmail.com

\begin{abstract}
Introduction: For Microscopic Grading of Infiltrating Ductal Carcinoma of Breast, various scoring systems are available in Cytology. In our present study, we have selected Robinson's scoring or grading system for comparison with Modified BloomRichardson's histological grading system in terms of concordance rate between both.

Material and Methods: The present study is done at the Department of Pathology, GMERS Medical College-Junagadh (Gujarat, India) from January 2015 to June 2018 and includes 50 diagnosed cases of Infiltrating Ductal Carcinoma of Breast. Diagnosis is based upon both cytological \& histological evaluation and includes microscopic grading, done by Robinson's System in Cytology and Elston \& Ellis modification of Bloom-Richardson System in Histology.

Result: Out of 50 cases, 8, 24 and 18 cases are of grade I, II and III tumor respectively on cytological evaluation and 6, 25 and 19 cases are of grade I, II and III tumor respectively on histological evaluation. The concordance rates between both systems for grade I, II and III tumor are 50.00\%, 83.33\% and 94.44\% respectively with Absolute concordance rate of $82.00 \%$.

Conclusion: Robinson's system is easy, effective \& comparable with Modified Bloom-Richardson's system. Both are helpful in Microscopic Grading of infiltrating ductal carcinoma of breast as an indicator of tumor behavior or aggressiveness.
\end{abstract}

Keywords: Cytological Grade, Histological Grade, Concordance Rate.

\section{Introduction}

Microscopic grading of Infiltrating Ductal Carcinoma of breast is essential as a part of laboratory diagnosis \& for prognosis. For the same, various histological \& cytological scoring or grading systems are available nowadays. For histological grading, Elston \& Ellis modification of Bloom and Richardson system is a widely accepted tumor grading system ${ }^{1}$ while various grading systems have been evolved based on the cytological features..$^{2-4}$ Out of various cytological grading systems, the system described by Robinson et $a l^{2}$ is found to be useful in grading breast carcinoma on fine needle aspiration (FNA) ${ }^{5-7}$

In this present study, we have evaluated Robinson's system for its easiness and effectiveness by comparing it with Modified Bloom-Richardson's system in terms of concordance rate between both. For statistical analysis in terms of Strength of Agreement, we have included Kappa ( $\kappa)$ statistics in our present study.

\section{Material and Methods}

The present study is done at the Department of Pathology, GMERS Medical College-Junagadh (Gujarat, India) from January 2015 to June 2018. It includes a total number of 50 cases of Infiltrating
Ductal Carcinoma of Breast diagnosed on both cytological as well as histological basis \& showing a definite cyto-histological correlation. Those cases that show no definite correlation between cytological \& histological diagnosis are not included in this present study. Cytological Diagnosis is based upon Patients' relevant clinical history, Gross examination of their breast lumps followed by fine needle aspiration (FNA) \& Microscopic examination of stained FNA smears while Histological Diagnosis is based upon Gross examination of Modified Radical Mastectomy (MRM) specimens and Microscopic examination of stained tissue sections obtained by various steps of histological laboratory techniques including fixation, dissection, tissue processing, paraffin embedding, microtomy, slide preparation and routine H-E staining. On basis of both gross \& microscopic findings, final diagnosis is given including grading \& staging of tumor.

During examination of Cytological (FNA) smears, scoring of grade is done by using Robinson's Grading System that includes six different criteria namely Cell Dissociation, Size of the Nucleus, Uniformity of Cells in size and shape, Nucleoli, Nuclear Margin \& Pattern of Nuclear Chromatin. Score 1, 2 or 3 is given separately for each criterion and ultimately Total score is calculated. Details are given below in Table 1.

Table 1: Robinson's Cytological Grading System

\begin{tabular}{|l|l|l|l|}
\hline \multicolumn{1}{|c|}{ Criterion } & \multicolumn{1}{c|}{ Score 1 } & \multicolumn{1}{c|}{ Score 2 } & \multicolumn{1}{c|}{ Score 3 } \\
\hline Cell Dissociation & Mostly Clusters & Clusters \& Single cells & Mostly Single Cells \\
\hline Nuclear Size & $\begin{array}{l}\text { 1-2 times size of } \\
\text { erythrocyte }\end{array}$ & 3-4 times size of erythrocyte & $\begin{array}{l}\text { 5 or more times size of } \\
\text { erythrocyte }\end{array}$ \\
\hline
\end{tabular}




\begin{tabular}{|l|l|l|l|}
\hline Cell Uniformity & Monomorphic & Mildly Pleomorphic & Pleomorphic \\
\hline Nucleoli & Indistinct/ Small & Noticeable & Abnormal/Distinct \\
\hline Nuclear Margin & Smooth & $\begin{array}{l}\text { Slightly Irregular/Folds and } \\
\text { Grooves }\end{array}$ & Buds and Clefts \\
\hline $\begin{array}{l}\text { Chromatin } \\
\text { Pattern }\end{array}$ & Vesicular & Granular & Clumped \& Cleaved \\
\hline
\end{tabular}

Total Score b/w 6 to 11:- Grade I, Total Score b/w 12 to 14:- Grade II \& Total Score b/w 15 to 18:- Grade III. During examination of Stained tissue sections, scoring of grade is done by using Elston \& Ellis modification of Bloom-Richardson Histological Grading System that includes three different criteria namely Formation of Tubules, Pleomorphism of Nuclei and Number of Mitosis per Ten High Power Fields. Score 1, 2 or 3 is given separately for each criterion and ultimately Total score is calculated. Details are given below in Table 2.

Table 2: Elston and Ellis modified Bloom-Richardson Grading System

\begin{tabular}{|l|c|c|c|}
\hline \multicolumn{1}{|c|}{ Criterion } & Score 1 & Score 2 & Score 3 \\
\hline Tubule formation & $>75 \%$ & $10-75 \%$ & $<10 \%$ \\
\hline Nuclear Pleomorphism & $\begin{array}{c}\text { Small, regular \& } \\
\text { uniform cells }\end{array}$ & $\begin{array}{c}\text { Moderate variation } \\
\text { in size/shape }\end{array}$ & $\begin{array}{c}\text { Marked nuclear } \\
\text { Pleomorphism }\end{array}$ \\
\hline $\begin{array}{l}\text { Mitosis per 10 h.p.f in } \\
\text { 44mm field diameter }\end{array}$ & $0-5$ & $6-10$ & 11 or more \\
\hline
\end{tabular}

Grade I - score 3-5 well differentiated;

Grade II- score 6-7 moderately differentiated;

Grade III - score 8-9 poorly differentiated.

Comparative evaluation is done between both systems and Concordance rates (both grade-wise and Absolute) are then calculated followed by calculation of Kappa $(\kappa)$ coefficient for each grade separately to compare the strength of agreement (statistical analysis).

\section{Results}

Total 50 diagnosed cases of Infiltrating Ductal Carcinoma have been included in this present study \& all of them are females. Out of them, 22 cases belong to age group of $41-50$ years. Youngest patient is 32 years old while eldest one is 85 years old. Distribution of cases according to their grading \& Comparison b/w two grading systems with Concordance Rate for each corresponding grade are mentioned below in Table 3.

Table 3: Distribution, Comparison \& Concordance Rates

\begin{tabular}{|c|c|c|c|c|c|}
\hline \multirow{2}{*}{$\begin{array}{c}\text { Robinson's } \\
\text { Grading }\end{array}$} & \multirow{2}{*}{$\begin{array}{l}\text { No. of cases in } \\
\text { Robinson's grading }\end{array}$} & \multicolumn{3}{|c|}{ No. of Cases in Modified Bloom-Richardson's } & Rate of \\
& & Grade I & Grade II & Grade III & $\begin{array}{c}\text { Roncordance } \\
\text { in \% }\end{array}$ \\
\cline { 3 - 6 } & 08 & 04 & 04 & ---- & 50.00 \\
\hline I & 24 & 02 & 20 & 02 & 83.33 \\
\hline II & 18 & ---- & 01 & 17 & 94.44 \\
\hline III & 50 & 06 & 25 & 19 & \\
\hline Total & 50 &
\end{tabular}

Overall or Absolute Concordance Rate of our present study is $82.00 \%$ (41 out of 50 cases).

Agreement between Robinson's and Modified Bloom-Richardson's Grading Systems using Kappa Statistics is mentioned below in Table 4.

Table 4: Standard Error \& Strength of Agreement

\begin{tabular}{|c|c|c|c|c|}
\hline Grade & $\begin{array}{c}\text { Kappa Value for } \\
\text { Concordance }\end{array}$ & $\begin{array}{c}\mathbf{9 5 \%} \text { Confidence } \\
\text { Interval }\end{array}$ & $\begin{array}{c}\text { Standard } \\
\text { Error }\end{array}$ & $\begin{array}{c}\text { Strength of } \\
\text { Agreement }\end{array}$ \\
\hline I & 0.504 & $0.132-0.876$ & 0.190 & Moderate \\
\hline II & 0.640 & $0.426-0.854$ & 0.109 & Substantial \\
\hline III & s.871 & $0.730-1.012$ & 0.072 & Almost Perfect \\
\hline
\end{tabular}

Results or Observations mentioned above in both Table $3 \& 4$ indicate almost perfect agreement between these two grading systems for Grade III Carcinoma or Poorly Differentiated Carcinoma followed by substantial agreement for Grade II Carcinoma or Moderately Differentiated Carcinoma. Moderate agreement is found for Grade I 
Carcinoma or Well Differentiated Carcinoma. So finally, we can say that in cases of poorly differentiated carcinoma (Grade III), various cytological and histological grading systems yield almost similar results. It is easy to diagnose poorly differentiated carcinoma on both cytological \& histological basis.

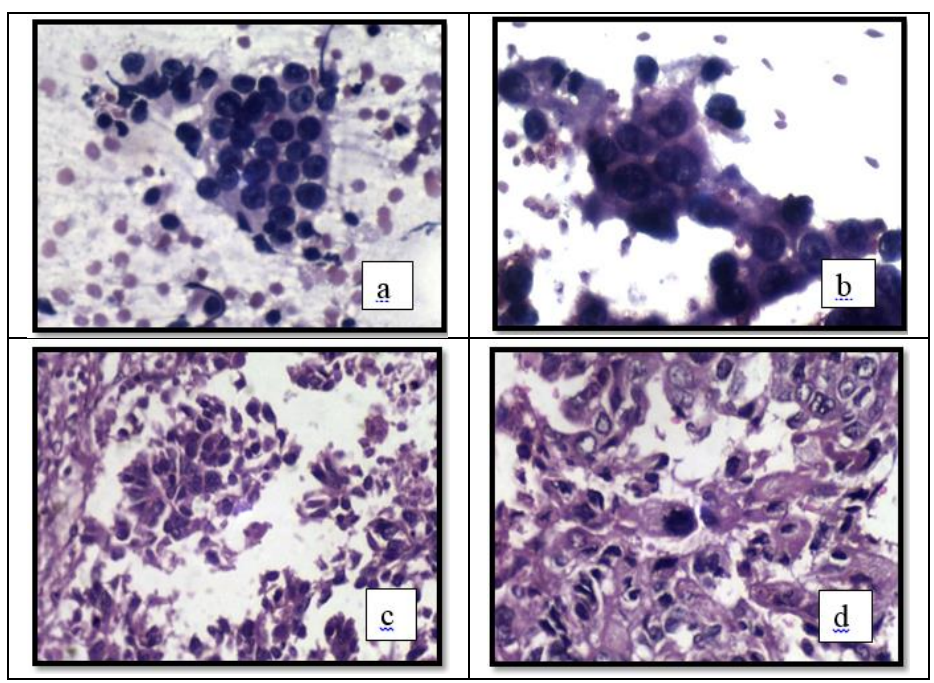

Fig. 1: Photomicrographs showing cytological and histological features of Breast Carcinoma (IDC): a) Breast Carcinoma with Moderate Differentiation and Cytological Grade II; b) Breast Carcinoma with Poor Differentiation and Cytological Grade III; c) Breast Carcinoma with Moderate Differentiation and Histological Grade II; d) Breast Carcinoma with Poor Differentiation and Histological Grade III

\section{Discussion}

Overall or Absolute Concordance Rate of our present study is $\mathbf{8 2 . 0 0 \%}$ (41 out of 50 cases). Comparison of Concordance Rates of various studies (including present study) is mentioned below in Table 5 .

Table 5: Comparison of concordance rates

\begin{tabular}{|c|l|c|c|c|c|c|}
\hline $\begin{array}{c}\text { Sr. } \\
\text { No. }\end{array}$ & Name of the Study & Year & \multicolumn{4}{|c|}{ Concordance Rate (\%) } \\
\cline { 4 - 7 } & & & Grade I & Grade II & Grade III & Absolute \\
\hline 1 & Present Study $_{2}$ & 2018 & 50.00 & 83.33 & 94.44 & 82.00 \\
\hline 3 & Kharwal AA et al $^{8}$ & 2016 & 100.00 & 85.71 & 100.00 & 93.33 \\
\hline 4 & Patel J et al $^{9}$ & 2009 & 92.30 & 83.30 & 91.70 & 89.10 \\
\hline 5 & Pradhan SP et al $^{11}$ & 2017 & 54.54 & 91.30 & 92.85 & 85.48 \\
\hline 6 & Kanth K et al $^{12}$ & 2017 & 84.61 & 79.16 & 87.50 & 83.60 \\
\hline 7 & Pandey P et al $^{13}$ & 2014 & 86.00 & 85.00 & 100.00 & 83.60 \\
\hline 8 & Gore CR et al $^{14}$ & 2013 & 100.00 & 81.81 & 75.00 & 83.33 \\
\hline 9 & Mustaphi RM et al $^{15}$ & 2014 & 62.50 & 88.90 & 88.90 & 80.76 \\
\hline 10 & Chavda A et al $^{16}$ & 2017 & 80.00 & 78.57 & 00.00 & 79.17 \\
\hline 11 & Pal S et al $^{17}$ & 2016 & 78.57 & 79.31 & 71.42 & 78.00 \\
\hline 12 & Pandya AN et al $^{18}$ & 2012 & 79.16 & 73.07 & 66.66 & 74.57 \\
\hline 13 & Phukan JP et al $^{19}$ & 2015 & 50.00 & 83.30 & 83.30 & 72.20 \\
\hline 14 & Sood N et al $^{20}$ & 2013 & 75.00 & 70.67 & 60.00 & 68.97 \\
\hline 15 & Chalise S et al $^{21}$ & 2015 & 45.00 & 80.00 & 72.70 & 65.90 \\
\hline
\end{tabular}

Comparative analysis of various similar studies mentioned above in Table 5 show significant similarity of Absolute Concordance Rates (\%). Total 9 out of 14 studies show similar results. Grade wise concordance rates show different results that are quite comparable for Grade II carcinoma \& for Grade III carcinoma up to some extent. For grade I carcinoma results are not comparable with that of our present study. So we can say that moderately differentiated carcinoma \& poorly differentiated carcinoma show comparable results on both cytological \& histological grading.

Kappa Values of our present study are 0.504, 0.640 and 0.871 for Grade I, II \& III tumors respectively. Other similar studies like those done by Sinha SK et al, ${ }^{22}$ Sood $\mathrm{N}$ et al, ${ }^{20}$ Pandya AN et al ${ }^{18}$ and Phukan JP et $\mathrm{al}^{19}$ also include Kappa Statistical Analysis in order to 
know about strength of agreement between corresponding grades. Out of them, Kappa Values of the study done by Sinha SK et $\mathrm{a}^{22}$ are $0.630,0.656$ and 0.829 for Grade I, II \& III tumors respectively and these values are comparable with the kappa values of our present study.

Our present study includes only one cytological grading system namely Robinson's system. There are many studies that include other cytological grading systems like those done by Arul P et $\mathrm{al}^{23}$ \& Einstien D et al. $^{24}$ Both include multiple cytological grading systems like Robinson, Mouriquand, Fisher, Taniguchi, Khan, Howell, Dabbs, etc. Among all these grading systems best results are obtained between Robinson's Cytological Grading system \& Modified BloomRichardson's Histological Grading system in terms of Absolute Concordance Rates, Kappa Values \& Strength of Agreement. Arul P et al ${ }^{23}$ reported $88.30 \%$ Absolute Concordance rate \& Substantial Agreement between these two popular grading systems with Kappa Value of 0.737. Einstien D et $\mathrm{al}^{24}$ reported $77.70 \%$ Absolute Concordance rate \& Substantial Agreement between these two popular grading systems with Kappa Value of 0.610. Thus, it is quite obvious that out of all cytological grading systems Robinson's system yields best result in terms of correlation \& concordance. So it is applicable $\&$ should be incorporated in our routine reporting practice based upon FNA smears.

\section{Conclusion}

Microscopic Grading plays an essential role in both diagnosis \& prognosis of Breast Carcinoma. It gives an idea about degree of differentiation \& aggressiveness of tumor. For Grading, we should use Robinson's method in cytology \& Modified Bloom-Richardson's method in histology because both are easy \& quite comparable methods. Pre-operative assessment of breast carcinoma is based upon clinical, radiological \& pathological (FNA) findings. Robinson's grading system is quite helpful in this assessment.

Funding: No funding sources.

Conflict of interest: None declared.

\section{References}

1. Elston CW, Ellis IO. Pathological prognostic factors in breast cancer. I. The value of histological grade in breast cancer: Experience from a large study with long-term follow-up. Histopathol 1991;19:403-10.

2. Robinson IA, McKee G, Nicholson A, D'Arcy J, Jackson PA, Cook MG, et al. Prognostic value of cytological grading of fine-needle aspirates from breast carcinomas. Lancet 1994;343:947-49.

3. Hunt CM, Ellis IO, Elston CW, Locker A, Pearson D, Blamey RW. Cytological grading of breast carcinoma - a feasible proposition? Cytopathol 1990;1:287-95.

4. Mouriquand J, Gozlan-Fior M, Villemain D, Bouchet Y, Sage JC, Mermet MA, et al. Value of cytoprognostic classification in breast carcinomas. J Clin Pathol 1986;39:489-96.
5. Robinson IA, McKee G, Kissin MW. Typing and grading breast carcinoma on fine-needle aspiration: Is this clinically useful information? Diagn Cytopathol 1995;13:260-65.

6. Pandit AA, Parekh HJ. Cytologic grading of breast carcinoma; comparison of four grading systems. J Cytol 2000;17:39-44.

7. Das AK, Kapila K, Dinda AK, Verma K. Comparative evaluation of grading of breast carcinomas in fine needle aspirates by two methods. Indian J Med Res 2003; 118:247-50.

8. Agarwal AA, Tambekar MY, Dhar R. Fine Needle Aspiration Cytology of Breast Carcinoma: A Comparative Study between Cytological and Histopathological Grading System with Lymph Node Status Assessment. IAIM, 2016;3(10):27-35.

9. Khan N, Afroz N, Rana F, Khan MA. Role of cytologic grading in prognostication of invasive breast carcinoma: $J$ Cytol 2009;26(2):65-8.

10. Patel J, Thorat R. Robinson cytological grading of breast carcinoma and its comparison with Elston's modification of Bloom-Richardson histopathological grading. Int $J$ Scientific Res 2017;6(8):224-27.

11. Pradhan SP, Dash A, Choudhury S, Mishra DP. Robinson's Cytological Grading on Aspirates of Breast Carcinoma and Correlation with Bloom-Richardson's Histological Grading. J Evid Based Med Healthcare 2017;4(2):86-91.

12. Kanth K, Satyanarayana V. Usefulness of Cytological grading in predicting tumor behavior in Breast carcinoma-An institutional experience. Ann Pathol Laboratory Med 2016;03(03):A-189-A-194

13. Pandey P, Dixit A, Chandra S, Kaur S. A Comparative and Evaluative Study of Two Cytological Grading Systems in Breast Carcinoma with Histological Grading: An Important Prognostic Factor. Analytical Cellular Pathol 2014; Article ID 767215, 6 pages

14. Gore CR, Chandanwale SS, Ruchika A, Shruti V, Anjali H D. Robinson cytological grading of breast carcinoma on fine needle aspiration cytology -An overview. Int $J$ Pharm Biol Sci 2013;3(2):564-70.

15. Mustaphi RM, Chowdhury S, Mondal S, Bhattacharya SK, Sarkar S, Saha TK. Role of Cytological Grading in Breast Cancer Prognosis and its Histo-pathological Correlation. IOSR-JDMS 2014;13(10):106-9.

16. Chavda A, Gandhi S, Dadhania B, Purohit T, Dhruva G. Comparison between cytological \& histological grading of Breast cancer and its role in prognosis. BJKinesNJBAS 2017;9(2):26-31.

17. Pal S, Gupta ML. Correlation between cytological and histological grading of breast cancer and its role in prognosis. J Cytol 2016;33(4):182-86.

18. Pandya AN, Shah NP. Comparative Evaluation of Robinson's Cytological Grading with Elston and Ellis' Nottingham Modification of Bloom Richardson Histopathology Grading for Breast Carcinoma. Natl J Community Med 2012;3(3):491-95.

19. Phukan JP, Sinha A, Deka JP. Cytological grading of breast carcinoma on fine needle aspirates and its relation with histological grading. South Asian J Cancer 2015;4(1):32-4.

20. Sood N, Nigam JS, Yadav P et al. Comparative study of cytomorphological Robinson's grading of breast carcinoma with Modified Bloom-Richardson histopathological grading. Pathol Res Int 2013;146542:15.

21. Chalise S, Jha A, Neupane PR, Pradhan SB, Pathak R. Correlation between Robinson's cytological grading with 
Modified Bloom-Richardson histopathological grading for Breast carcinoma. J Pathol Nepal 2015;5:791-97.

22. Sinha SK, Sinha N, Bandyopadhyay R, Mondal SK. Robinson's cytological grading on aspirates of breast carcinoma: Correlation with Bloom Richardson's histological grading. J Cytol 2009;26(4):140-43.

23. Arul P, Masilamani S. Comparative evaluation of various cytomorphological grading systems in breast carcinoma. Indian J Med Paediatr Oncol 2016;37(2):79-84.
24. Einstien D, Omprakash BOP, Ganapathy H, Rahman S. Comparison of 3-Tier Cytological Grading Systems for Breast Carcinoma. ISRN Oncol 2014;2014:252103.

How to cite this article: Menapara C., Kokani M. Evaluation of Robinson's cytological grading by comparing it with modified Bloom-Richardson's histological grading for infiltrating ductal carcinoma of Breast. J Diagn Pathol Oncol 2018;3(4):248-52. 